\title{
A Comparative Study between No Touch Blepharoplasty and Direct Transcutaneous Lower Eyelid Blepharoplasty Using Orbicularis Oculi Muscle Flap
}

\author{
SOHA F. EL-MEKKAWY, M.D. \\ The Department of Plastic Surgery, Ain Shams University, Cairo, Egypt
}

\begin{abstract}
Introduction: Lower blepharoplasty is considered one of the puzzling procedures in plastic surgery and the search of one ideal technique is going on, thus we performed this prospective study in order to compare the functional and aesthetic outcomes of 2 different blepharoplasty techniques.

Methods: 40 patients requesting blepharoplasty were divided randomly into 2 sub-groups in respect to the technique used; the traditional blepharoplasty or the no touch technique.

Results: The overall rate of incidence of complications was $22.5 \%$. No statistically significant difference in-between the 2 groups.

Conclusion: The no touch technique; through our experience in this study; has proven to be a safe, successful and efficacious technique for lower eyelid rejuvenation.
\end{abstract}

Key Words: No touch - Blepharoplasty - Lower eyelid - Orbicularis.

\section{INTRODUCTION}

Since decades; there is always a steady increase in the demand for lower eye lid rejuvenation although being the most challenging procedures in plastic surgery [1].

The complications of blepharoplasty blindness, chronic lower eyelid edema, dry eye, resistant ecchymosis, excess fat excision, eyelid malposition, allergic reactions and residual fat bags [2]. Complications are usually uncommon, however even the thought of having any of them; has led many patients to think about any other method for periorbital rejuvenation and also had led surgeons to alter their techniques to accommodates the needs of the patients with minimal complications [3].

Every single surgical technique should be built upon the aging deformities in the anatomical structure of eyelid and should care for patients' complaints and expectations [4]. There are two chief trends in blepharoplasty, one toward more aggressive techniques to get the maximum aesthetic outcome and the other one toward more conservative techniques to decrease incidence rate of complications $[\mathbf{5 , 6}]$.

The conservative techniques are mainly represented by the transconjunctival approach but it has several limitations; it does not appropriately target the lateral pocket of fat, it does not correct the aging changes of eyelid other than fat protrusion like skin wrinkles, canthal laxity, or the tear trough deformity $[\mathbf{7 , 8}]$. So to enhance the aesthetic outcome, most surgeons adopted the direct transcutaneous approach, however this increased the post blepharoplasty complications especially lid malposition $[9,10]$.

Several causes have been incriminated; denervation of the orbicularis occuli muscle, vertical deficiency of the anterior or posterior lamella or cicatrization of orbital septum. To solve this problem, a variety of techniques has been advocated; Fagien reported the lateral retinacular suspension concept as a canthal support [11]. Codner et al., reported the routine lateral canthal support concept in the form of canthopexy or canthoplasty [12] and the no touch lower blepharoplasty techniques [13].

We performed this study in order to offer a minimally invasive approach to correct undesirable changes that affects lower eyelids with a high satisfaction rate and a lower range of complications through comparing the final outcomes of 2 different techniques of lower eye lid blepharoplasty.

\section{PATIENTS AND METHODS}

This new comparative study was performed on 40 patients; coming requesting blepharoplasty, in the period from January 2013 to January 2015.

Detailed clinical history (comorbidities, medication, past, personal and family members), ocular 
examination to determine if there are ocular conditions that could complicate surgery (dry eye syndrome, visual fields) and analysis of periorbital region concerning; eye brow position, eyelid skin quality, lid margin position, retraction, orbital fat, lacrimal gland. The analysis of the patient's psychological aspects and the patient's expectations regarding surgery are also very important. Standard photographs are obtained; close up and full face frontal and lateral view.

Exclusion criteria: Previous surgery for transcutaneous or transconjunctival lower blepharoplasty, midface lift, lower lid tumors, Graves' disease, dry eye syndrome, psychiatric disorders, patients with impractical hopes and patients with history of previous eyelid surgery.

\section{The patients are divided randomly into 2 groups:}

- Group A: Trans-cutaneous lower eye-lid blepharoplasty via the conventional sub-ciliary incision using the skin muscle flap technique together with orbicularis oculi muscle suspension.

- Group B: The no touch lower eye-lid blepharoplasty.

\section{Surgical technique:}

- Upper eyelid access for lateral lower eye lid fat removal.

- Inferior retinacular canthopexy/plasty.

- Trans-conjunctival retro-spetal access.

- Fat manipulation; excess fat is excised through the trans-conjunctival approach.

- The lateral pocket of fat is excised via the upper blepharoplasty incision.

- Arcus marginalis incision and release.

- Skin incision; the excess skin is removed through sub-ciliary incision.

- Trans-canthal canthopexy; the lateral pocket fat is excised through upper blepharoplasty incision.

Patients' evaluation: Both groups of patients were compared with preoperative photographs, and after postoperative 1, 4, and 12 weeks. (Figs. 1,2).

Patients were evaluated by the operating surgeon as regard complications in the form of orbital hematoma, blepharitis, ecchymosis, granuloma, lid retraction, ectropion.

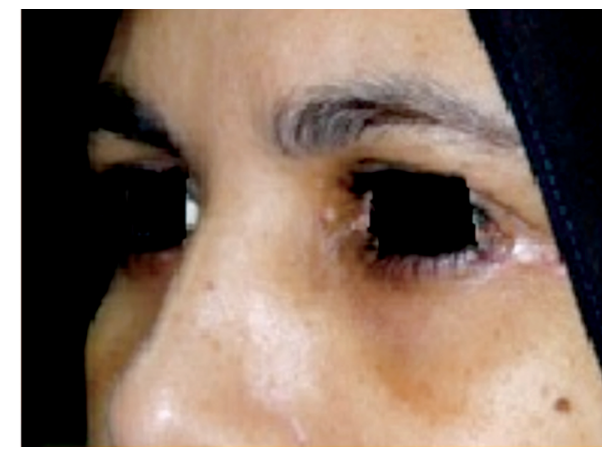

Fig. (1): A 38 year old female patient who underwent no touch lower blepharoplasty.
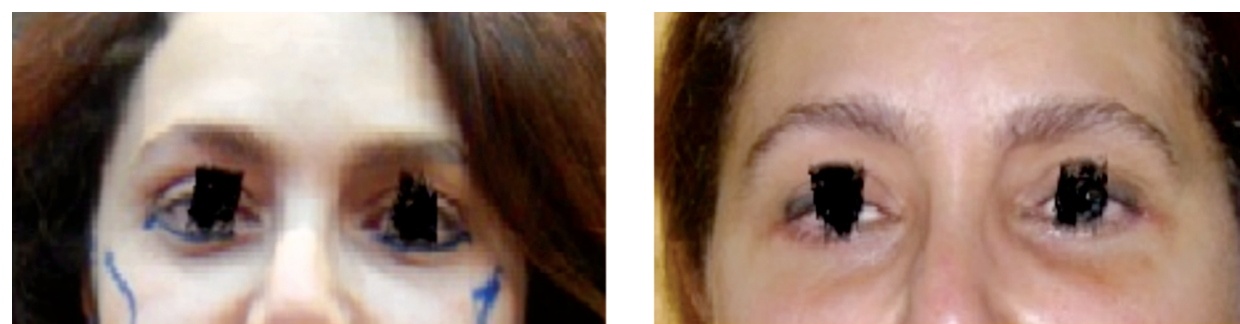

Fig. (2): A 42 year old female patient who underwent transcutaneous lower blepharoplasty

\section{RESULTS}

Of the 40 patients involved in the study, $90 \%$ $(n=36)$ were females and $10 \%(n=4)$ were males, with age ranging between 32 to 60 years (mean= 45.4). The overall rate of complications was $22.5 \%$ (9 patients).
Incidence of complications in group A was $20 \%$ $(n=4)$, which was not statistically significant high in comparison to group $\mathrm{B}$, at $25 \%(\mathrm{n}=5)$. The complications found in group A were: 1 patient with lid support suture requiring removal; 1 case $(6 \%)$ of ecchymosis that resolved spontaneously within 2 weeks; 6 patients (3\%) with lower eye- 
lid retraction that was resolved with massage and 1 case with residual excess fat that was treated conservatively.

The complications found in group B were: 3 cases of ecchymosis that resolved spontaneously within a month; 1 patient had granuloma that was excised under local anaesthesia and 1 patient with lower eye-lid retraction that required revision under local anesthesia and sedation after 15 months. Table (1).

Table (1): Postoperative complications and revisions.

\begin{tabular}{lcc}
\hline Complications & Group A & Group B \\
\hline Orbital hematoma & $0 / 20$ & $0 / 20$ \\
Blepharitis & $0 / 20$ & $0 / 20$ \\
Ecchymosis & $1 / 20$ & $3 / 20$ \\
Granuloma/cyst excision & $0 / 20$ & $1 / 20$ \\
Scar requiring revision & $0 / 20$ & $0 / 20$ \\
Lid support suture requiring removal & $1 / 20$ & $0 / 20$ \\
Lid retraction: & & \\
$\quad$ Mild (resolved with massage) & $1 / 20$ & $0 / 20$ \\
$\quad$ Requiring revision & $0 / 20$ & $1 / 20$ \\
Residual excess fat & $1 / 20$ & $0 / 20$ \\
Ectropion & $0 / 20$ & $0 / 20$ \\
\hline
\end{tabular}

\section{DISCUSSION}

Aging process usually affects all structures of the three lamellae of the lower eye-lid; skin, orbicularis occuli muscle, the tarsus, fat and ligaments. Aging results in atrophy of fat, weakness of the ligaments, and resorption and apposition of bony surfaces and malposition of eye-lid [14].

Thus, ideal rejuvenation of these diverse structures requires distinct and detailed surgical correction according to their own demands during blepharoplasty procedure [15]. The skin must be carefully excised and re-draped, the muscle must be strengthened, the fat must be minimally removed and the eye-lid should be suspended as a whole [16].

Historically, standard lower eye-lid blepharoplasty was performed via sub-cilliary incision with skin and muscle flap, herniated fats excision with the removal of the excess skin and muscle [17]. Disadvantages of this technique are; convex lower lid, no improvement of the tear trough area in addition to lid-ectropion due to injured motor innervation to orbicularis oculi muscle [18].

Another variation is the trans-conjunctival approach in which re-distribution of fat is done. The disadvantages are that it does not allow muscle manipulation, does not correct anterior lamella excess although laser resurfacing can be done to correct minimal redundant skin to further enhance final aesthetic result and also placement of sutures to stabilize the repositioning of the fat in a supraperiosteal pocket is difficult [19].

Ouattara et al., [20], studied the anatomical differences in innervation of orbicularis occuli muscle and they found that the muscle is supplied through two plexuses; the superior one was formed by union of temporal and superior zygomatic branches while the inferior one was usually formed by union of inferior zygomatic and superior buccal branches.

Difrancesco et al., [21], had performed preoperative and post-operative videography and electromyography to assess innervation to orbicularis occuli following trans-cutaneous lower eye lid blepharoplasty and they found that conventional sub-ciliary incision does not cause denervation of pre-tarsal orbicularis occuli.

In our study, group (a) orbicularis occuli muscles were evaluated clinically in the postoperative period and we found no for any sign of nerve injury and thus our study concluded that the argument regarding the dennervation of the muscle; showed that it is not of insignificant clinical value.

Innocenti et al., [16], analyzed the effect of anchoring the orbicularis occuli as a flap to the superior orbital rim during transcutaneous blepharoplasty and they found that all patients treated by this technique showed a minimally cranial move of the lower eye lid and thus efficiently stabilizes its position after transcutaneous blepharoplasty with a natural cosmetic appearance.

Complication rates in the present study are almost the same as in well trained hands in various studies, however, limitations of the no touch technique are, orbicularis hypertrophy, technical difficulty, extent of the procedure. To accomplish a safe lower blepharoplasty; leave the muscle \& septum intact or get trained to master a method of lid support.

\section{Conclusion:}

The no touch technique; through our experience in this study; has proven to be a safe, successful and efficacious technique for lower eye lid rejuvenation.

\section{REFERENCES}

1- Hartstein M.E. and Kikkawa D.: How to Avoid Blepharoplasty Complications. Oral Maxillofacial Surg. Clin. N. Am., 21: 31-41, 2009. 
2- Collar R., Lyford-Pike S. and Byrne P.: Algorithmic approach to lower lid blepharoplasty. Facial Plastic Surgery. February, 29 (1): 32-39, 2013.

3- Morax S. and Touitou V.: Complications of blepharoplasty. Orbit., 25 (4): 303-18, 2006.

4- Jelks G.W. and Jelks E.B.: Preoperative evaluation of the blepharoplasty patient. Bypassing the pitfalls. Clin. Plast. Surg., 20 (2): 213-23, 1993

5- Netscher D.T., Patrinely J.R. and Peltier M. et al.: Transconjunctival versus transcutaneous lower eyelid blepharoplasty: a prospective study. Plast. Reconstr. Surg., 96: 1053-60, 1995

6- Jacono A.A. and Moskowitz B.T.: Ransconjunctival versus transcutaneous approach in upper and lower blepharoplasty. Facial. Plast. Surg., 17: 21-8, 2001.

7- Camirand A., Doucet J. and Harris J.: Eyelid aging: The historical evolution of its management. Aesthet. Plast. Surg., 29: 65-73, 2005.

8- Goldberg R.A.: Transconjunctival orbital fat repositioning: Transposition of orbital fat pedicles into a subperiosteal pocket. Plast. Reconstr. Surg., 105: 743-51, 2000.

9- McGraw B.L. and Adamson P.A.: Postblepharoplasty ectropion: Prevention and management. Arch. Otolaryngol. Head. Neck Surg., 117: 852-6, 1991.

10- Patipa M.: The evaluation and management of lower eyelid retraction following cosmetic surgery. Plast Reconstr Surg., 106: 438- 53, 2000.

11- Fagien S.: Algorithm for canthoplasty: The lateral retinacular suspension: A simplified suture canthopexy. Plast. Reconstr. Surg. Jun., 103 (7): 2042-53; discussion 20548, 1999.

12- Codner M.A., Wolfli J.N. and Anzarut A.: Primary transcutaneous lower blepharoplasty with routine lateral canthal support: A comprehensive 10-year review. Plast. Reconstr. Surg. Jan., 121 (1): 241-50, 2008.

13- Jelks G.W., Glat P.M., Jelks E.B. and Longaker M.T.: The inferior retinacular lateral canthoplasty: a new technique. Plast Reconstr Surg. Oct., 100 (5): 1262-70, discussion 1271-5, 1997.

14- Pottier F., El-Shazly N.Z. and El-Shazly A.E.: Aging of the orbicularis oculi: Anatomophysiologic consideration in upper blepharoplasty. Arch. Facial. Plast. Surg., 10: 346-9, 2008.

15- Subramanian N.: Blepharoplasty. Indian J. Plas.t Surg. 41 (Suppl): S88e92, 2008.

16- Innocenti A., Mori F., Melita D., et al.: Effects of orbicularis oculi flap anchorage to the periosteum of the upper orbital rim on the lower eyelid position after transcutaneous blepharoplasty: Statistical analysis of clinical outcomes.

17- Castanares S.: Blepharoplasty for herniated intraorbital fat: Anatomical basis for a new approach. Plast. Reconstr. Surg., 1951; 8: 46-58, 1946.

18- Ilankovan V.: Aesthetic blepharoplasty. British Journal of Oral and Maxillofacial Surgery, 48: 493-497, 2010

19- Fincher F.E. and Moy R.L.: Cosmetic Blepharoplasty. Dermatol Clin., Jul., 23 (3): 431-42, vi, 2005.

20- Ouattara D., Vacher C., de Vasconcellos J.J., Kassanyou S., Gnanazan G. and N'Guessan B.: Anatomical study of the variations in innervation of the orbicularis oculi by the facial nerve. Surg. Radiol. Anat. Feb., 26 (1): 51-3., 2004

21- DiFrancesco L.M.1., Anjema C.M., Codner M.A., McCord C.D. and English J.: Evaluation of conventional subciliary incision used in blepharoplasty: Preoperative and postoperative videography and electromyography findings. Plast. Reconstr. Surg. Aug., 116 (2): 632-9, 2005. 